\title{
Modeling and Numerical Simulation of Heat Transfers in a Metallic Pressure Cooker Isolated with Kapok Wool
}

\section{Drissa Ouedraogo ${ }^{1}$, Serge Wendsida Igo² ${ }^{2}$, Gaël Lassina Sawadogo ${ }^{1}$, Abdoulaye Compaore ${ }^{2}$, Belkacem Zeghmati ${ }^{3}$, Xavier Chesneau ${ }^{3}$}

\author{
${ }^{1}$ Laboratoire d'Energies Thermiques Renouvelables (LETRE), Université Joseph KI-ZERBO, Ouagadougou, Burkina Faso \\ ${ }^{2}$ Département Energie, Institut de Recherche en Sciences Appliquées et Technologies (IRSAT/CNRST), \\ Ouagadougou, Burkina Faso \\ ${ }^{3}$ Laboratoire de Mathématiques et Physique (LAMPS), Université de Perpignan Via Domitia, Perpignan, France \\ Email: *ouedraogodri2016@gmail.com
}

How to cite this paper: Ouedraogo, D., Igo, S.W., Sawadogo, G.L., Compaore, A., Zeghmati, B. and Chesneau, X. (2020) Modeling and Numerical Simulation of Heat Transfers in a Metallic Pressure Cooker Isolated with Kapok Wool. Modeling and $\mathrm{Nu}$ merical Simulation of Material Science, 10, $15-30$.

https://doi.org/10.4236/mnsms.2020.102002

Received: March 29, 2020

Accepted: April 25, 2020

Published: April 28, 2020

Copyright $\odot 2020$ by author(s) and Scientific Research Publishing Inc. This work is licensed under the Creative Commons Attribution International License (CC BY 4.0).

http://creativecommons.org/licenses/by/4.0/

\begin{abstract}
In this work, a numerical study of heat transfers in a metallic pressure cooker isolated with kapok wool was carried out. This equipment works like a thermos, allowing finishing cooking meals only thanks to the heat stored at the beginning of cooking, which generates energy savings. Cooked meals are also kept hot for long hours. In our previous work, we have highlighted the performances of the pressure cooker when making common dishes in Burkina Faso. Also, the parameters (thickness and density) of the insulating matrix allowing having such performances as well as the influence of the climatic conditions on the pressure cooker operation were analyzed in detail in this present work. The numerical methodology is based on the nodal method and the transfer equations obtained by making an energy balance on each node have been discretized using an implicit scheme with finite differences and resolved by the Gauss algorithm. Numerical results validated experimentally show that the thickness of the kapok wool as well as its density play an important role in the pressure cooker operation. In addition, equipment performances are very little influenced by the weather conditions of the city of Ouagadougou (Burkina Faso).
\end{abstract}

\section{Keywords}

Pressure Cooker, Kapok Wool, Heat Transfers, Modeling, Nodal Method

\section{Introduction}

Thermal insulation is one of the most used solutions to save energy in different 
sectors (building, catering, industry, etc.). In many sectors, natural insulation is more and more preferred over synthetic insulation because of the requirements related to sustainable development. Natural insulators can be vegetable, animal or mineral origin. Among these natural insulators that are found in abundance in tropical countries like Burkina Faso, is kapok wool. Numerous studies have demonstrated the ability of this fiber to compete with synthetic insulation.

Experimental studies conducted by Voumbo et al. [1] on kapok wool, using the plate method, show very interesting thermophysical properties. Indeed, they have shown that the thermal conductivity of kapok wool varies between 0.03 and $0.04 \mathrm{~W} / \mathrm{m} \cdot \mathrm{K}$ for a density between 5 and $40 \mathrm{~kg} / \mathrm{m}^{3}$ and an average thermal diffusivity of $17.1 \times 10^{-7} \mathrm{~m}^{2} / \mathrm{s}$.

J. C. Damfeu et al. [2] determined by an experimental measurement using the radial flux method the thermo-physical properties at low density of the following natural fibers: fibers kapok; peanut shell fibers; rattan fiber and coconut fiber. The results presented show that the thermal conductivity of kapok wool $(\lambda=$ $0.045 \mathrm{~W} / \mathrm{m} \cdot \mathrm{K})$ is in agreement with that reported by Voumbo et al. [1].

A. Wereme et al. [3] compared the storage capacity of ice in a container insulated with kapok wool and in the shell of a refrigerator insulated with polyurethane. They found that the insulated container with kapok wool could keep the ice for 6 days while the shell of the refrigerator could do it in 7 days, which shows that kapok wool can compete with polyurethane.

In the same way aming Wang, [4] experimentally analyzed the heat transfer in the kapok using a sensor (HIH-3610). It appears that the use of kapok as a thermal insulating material in the fabric helps minimize heat loss from the human body. The influence of temperature and wind speed on heat transfer through the kapok was analyzed and compared to that of cotton. It has been shown that with kapok the heat losses of the human body are lower than those obtained by cotton.

In the building sector, a study focused on a comparative analysis of the thermal performance of a non-insulated house with that of a house whose roof is insulated with kapok fiber shows that kapok fiber is suitable for insulating the roof in residential buildings in a hot climate [5].

Other work has shown that the combination of kapok wool and other materials can lead to very interesting materials in terms of thermal insulation. Adulkareem S et al. [6] show through an experimental study that composite materials resulting from the combination of kapok wool and sugarcane bagasse or coconut fiber at percentages of $50 \%$ lead to very good insulating materials, have shown that adding a small amount of kapok wool to the plaster leads to an improvement in the thermophysical properties of the composite material [1].

Because of its very interesting thermophysical properties, we have recently used kapok wool in the thermal insulation of a pressure cooker intended for cooking and meals conservation. The experimental study by Drissa Ouedraogo et al. [7] which followed showed that the device makes it possible to achieve 
enormous energy savings (between $30 \%$ and $75 \%$ ) in the cooking of local dishes, and its constant time is about 60 hours. However, even if these results are mainly due to the thermophysical properties of kapok wool, the influence of other parameters such as the thickness and density of the insulating matrix on the performance of the device was not elucidated during this study. However, these parameters are essential when reproducing or resizing the device. In addition, the behavior of the pressure cooker in a typical climate of Burkina Faso, throughout the year is not known, which could limit its application in a given period. Consequently, the objective of this work is to carry out a numerical simulation in order on the one hand to understand the influence of the parameters (thickness, density) of the insulating matrix on the operation of the device and on the other hand to know the influence of the climate on his behavior during the year.

\section{Pressure Cooker Modeling}

\subsection{Description of the Pressure Cooker}

The pressure cooker has a parallelepipedic shape $(L \times W \times H=65 \mathrm{~cm} \times 60 \mathrm{~cm} \times$ $50 \mathrm{~cm}$ ) box made of $2 \mathrm{~mm}$ thick steel sheet which encloses the insulation system consisting of kapok wool. The thickness of kapok wool varies from 1 to $20 \mathrm{~cm}$ while its density varies from 10 to $50 \mathrm{~kg} / \mathrm{m}^{3}$. The kapok wool is protected from the outer wall by a $15 \mathrm{~mm}$ thick wooden sheet. The pot containing hot water is placed in the middle of the pressure cooker and surrounded by kapok wool (Figure 1).

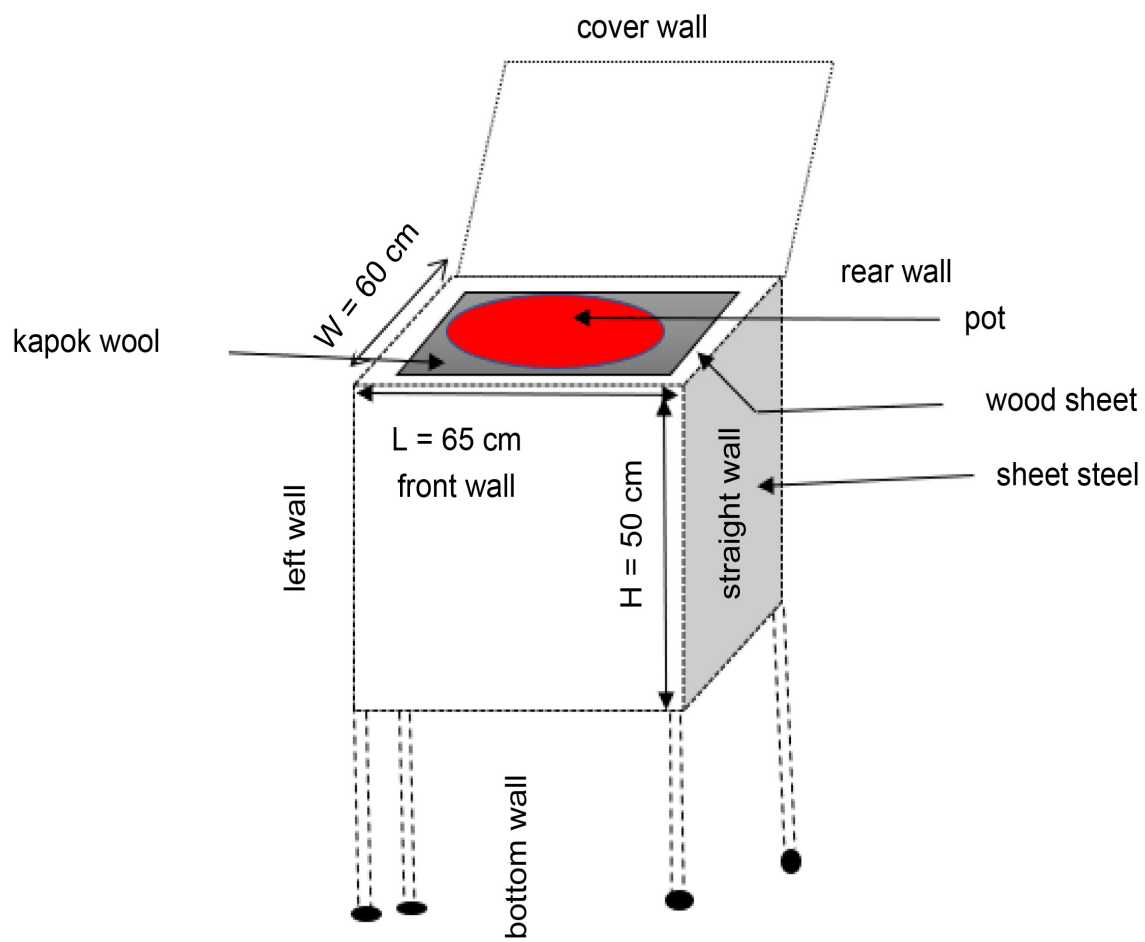

Figure 1. Description of the pressure cooker. 


\subsection{Mathematical Formulation}

\subsubsection{Simplifying Hypotheses}

We adopt the following simplifying hypotheses:

- The hot water temperature inside the pressure cooker is uniform;

- The thermo-physical properties of air and materials are constant;

- The external temperature is taken equal to the ambient temperature;

- Heat exchanges through the cover wall are negligible;

- Materials are assimilated to gray bodies;

- The celestial vault is considered to be a black body;

- The atmospheric diffuse radiation is isotropic.

According to the above hypotheses, the model of heat transfers in the pressure cooker is represented in the Figure 2.

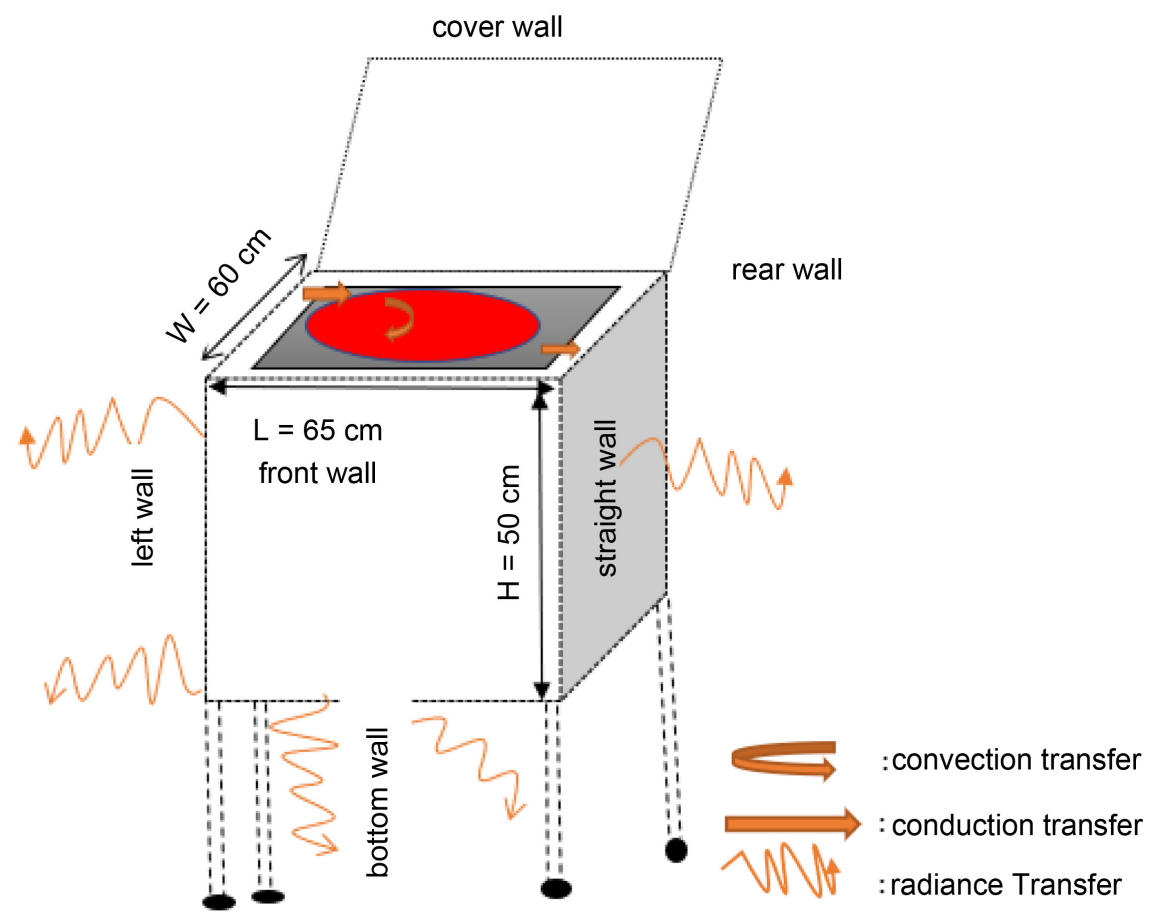

Figure 2. Pressure cooker heat transfer model.

\subsubsection{Heat Transfers Equations in the Pressure Cooker}

In general, modeling a thermal system using the nodal method amounts to setting up a network of thermal capacities $\left(C_{i}=\rho_{i} V_{i} C_{p i}\right)$, heat sources and thermal coefficients. Heat transfers are represented by a thermal resistance network. By applying Kirchhoff's law [8], to the network of thermal resistances schematizing the different modes of heat transfer, we give the general heat balance equation by expression (1). This equation is based on nodal analysis by Boyer et al., [9] and Thomas Nganyaa et al. [10].

$$
m_{i} C_{p i} \frac{\partial T_{i}}{\partial t}=\sum_{i \neq j} G_{i j x} S\left(T_{j}-T_{i}\right)+Q_{i}
$$

With: 
$j$ index of the medium for which $T_{j}$ is a potential connected to the potential $T_{i}$, $Q_{i}$ heat source $(\mathrm{W}), G_{i j x}$ heat transfer coefficient between the media $i$ and $j$ $\left(\mathrm{W} / \mathrm{m}^{2} \mathrm{~K}\right)$ according to the heat transfer mode $x$ (conduction, convection, radiation) and $S$, surface of the section considered $\left(\mathrm{m}^{2}\right)$. The thermal heat transfer coefficients $G_{i j x}$ are defined by the formal expression of the energy flow $\Phi_{i j}$, exchanged between two adjacent nodes $i$ and $j$

$$
\Phi_{i j}=G_{i j x}\left(T_{i}-T_{j}\right)
$$

Figure 3 show the heat transfer model.

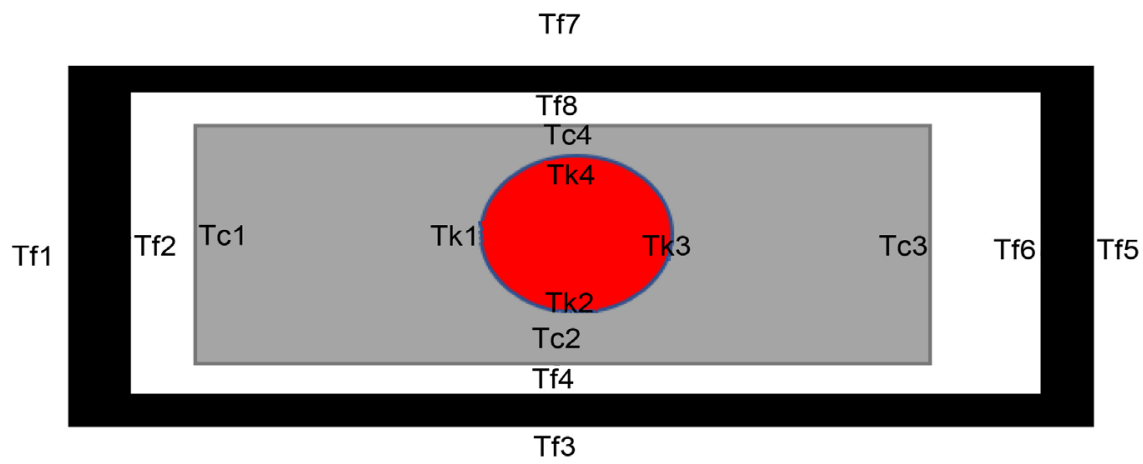

Figure 3. Pressure cooker heat transfer model.

The heat transfer equations resulting from the nodal model of the pressure cooker are summarized below:

- At the sheet steel

- The external face of the pressure cooker

$$
\frac{m_{f} C_{p}}{S} \frac{\partial T_{f i}}{\partial t}=\sum h_{c v}\left(T_{a m b}-T_{f i}\right)+h_{r, \text { ciel }}\left(T_{\text {ciel }}-T_{f i}\right)+\frac{\lambda_{f}}{e_{f}}\left(T_{f j}-T_{f i}\right)
$$

- The inner side of the pressure cooker

$$
\frac{m_{f} C_{p}}{S} \frac{\partial T_{f j}}{\partial t}=\frac{\lambda_{f}}{e_{f}}\left(T_{f j}-T_{f i}\right)+\frac{\lambda_{c}}{e_{c}}\left(T_{c i}-T_{f j}\right)
$$

- At the wood sheet level

$$
\frac{m_{c} C_{c}}{S} \frac{\partial T_{c i}}{\partial t}=\frac{\lambda_{c}}{e_{c}}\left(T_{f j}-T_{c i}\right)+\frac{\lambda_{k}}{e_{k}}\left(T_{k i}-T_{c i}\right)
$$

- At the kapok level

$$
\frac{m_{k} C_{k}}{S} \frac{\partial T_{k i}}{\partial t}=\frac{\lambda_{c}}{e_{c}}\left(T_{c i}-T_{k i}\right)+h_{0 i n t}\left(T_{c i}-T_{0}\right)
$$

- Within the pot

$$
\frac{m_{w} C_{w}}{S} \frac{\partial T_{0}}{\partial t}=\sum h_{0 i n t}\left(T_{k i}-T_{0}\right)
$$

\subsubsection{Expressions of Heat Transfer Coefficients}

The heat exchanges in the pressure cooker take place according to the three 
modes (convective, radiative and by conduction).

The convective exchange coefficient between the outer wall of the pressure cooker and the ambient air depends on the action of the wind speed. This coefficient $h_{c V}$ is deduced from the relation of Mac Adams [11] [12].

$$
h_{c v}=5.67+3.86 \mathrm{~V}
$$

- The heat transfer coefficients by natural convection between the interior air of the pressure cooker enclosure and the walls are determined thanks to the correlations deduced in the case of a vertical wall [13] [14].

$$
N_{u}=0.68+0.67 R_{a}^{1 / 4}\left[1+\left(\frac{0.492}{P_{r}}\right)^{9 / 16}\right]^{-4 / 9} ; 10^{-5} \leq R_{a} \leq 10^{12}
$$

- The heat transfer coefficient between the underside of the horizontal wall of the pot and the ambient air is deduced from the relation of Incroprera \& De Witt [15].

$$
N_{u}=0.27 R_{a}^{1 / 4}, 10^{5} \leq R_{a} \leq 10^{10}
$$

- The coefficient of radiative transfer between the external wall of the pressure cooker and the celestial vault is determined by the Expression (11):

$$
h_{r-p-c i e l}=\frac{\sigma}{\frac{1}{\varepsilon_{p}}+\frac{1}{F_{\text {ciel }}}-1}\left(T_{f i}^{2}+T_{\text {ciel }}^{2}\right)\left(T_{f i}+T_{\text {ciel }}\right)
$$

In the case of a vertical wall, the radiative form factor $F_{s k y}$ verifies the expression determineted by Ivanova et al. [16] and J. Ramirez et al. [17].

$$
F_{\text {sky }}=\frac{3 \pi+2 b}{2 \pi(3+2 b)}
$$

$b$ : represents a parameter which is a function of the anisotropy of the sky. For an isotropic sky $(b=0)$ the radiative from factor is equal to 0.5 . In the literature, there are several correlations for determining the temperature of the sky. We selected the one proposed by Swinbank [18].

$$
T_{\text {sky }}=0.0552 T_{a m b}^{1.5}
$$

\subsection{Discretization of Equations}

The Equations (3)-(7) are discretized by an implicit method with finite differences. This method is based on a Taylor series development which transforms partial differential equations into a system of algebraic equations. So, the discretized equations are given by the Expressions (13)-(22).

- At the sheet steel level

- The external face of the pressure cooker

$$
\begin{aligned}
& \frac{m_{f} C_{p f}}{S} \times \frac{T_{f i}^{t+\Delta t}-T_{f i}^{t}}{\Delta t} \\
& =h_{c v i}\left(T_{a m b}^{t+\Delta t}-T_{f i}^{t+\Delta t}\right)+\frac{\lambda_{f}}{e_{f}}\left(T_{f j}^{t+\Delta t}-T_{f i}^{t+\Delta t}\right)+h_{r-p l-c i e l}\left(T_{c i e l}^{t+\Delta t}-T_{f i}^{t+\Delta t}\right)
\end{aligned}
$$




$$
\begin{aligned}
& \left(\frac{m_{f} C_{p f}}{S}+h_{c v i}+h_{r-p l-c i e l}\right) T_{f i}^{t+\Delta t}-\frac{\lambda_{f}}{e_{f}} T_{f j}^{t+\Delta t}-h_{r-p l-c i e l} T_{\text {ciel }}^{t+\Delta t}-h_{\text {cvi }} T_{a m b}^{t+\Delta t} \\
& =\frac{m_{f} C_{p f}}{S} T_{f i}^{t}
\end{aligned}
$$

- The inner side of the pressure cooker

$$
\begin{gathered}
\frac{m_{f} C_{p f}}{S} \times \frac{T_{f j}^{t+\Delta t}-T_{f j}^{t}}{\Delta t}=\frac{\lambda_{f}}{e_{f}}\left(T_{f j}^{t+\Delta t}-T_{f i}^{t+\Delta t}\right)+\frac{\lambda_{c}}{e_{c}}\left(T_{c i}^{t+\Delta t}-T_{f j}^{t+\Delta t}\right) \\
\left(\frac{m_{f} C_{p f}}{S}+\frac{\lambda_{f}}{e_{f}}+\frac{\lambda_{c}}{e_{c}}\right) T_{f j}^{t+\Delta t}-\frac{\lambda_{f}}{e_{f}} T_{f i}^{t+\Delta t}-\frac{\lambda_{c}}{e_{c}} T_{c i}^{t+\Delta t}=\frac{m_{f} C_{p f}}{S} T_{f j}^{t}
\end{gathered}
$$

- At the wood sheet

$$
\begin{gathered}
\frac{m_{c} C_{p c}}{S} \times \frac{T_{c i}^{t+\Delta t}-T_{c i}^{t}}{\Delta t}=\frac{\lambda_{c}}{e_{c}}\left(T_{f j}^{t+\Delta t}-T_{c i}^{t+\Delta t}\right)+\frac{\lambda_{k}}{e_{k}}\left(T_{k i}^{t+\Delta t}-T_{c i}^{t+\Delta t}\right) \\
\left(\frac{m_{c} C_{p c}}{S}+\frac{\lambda_{f}}{e_{f}}+\frac{\lambda_{k}}{e_{k}}\right) T_{c i}^{t+\Delta t}-\frac{\lambda_{f}}{e_{f}} T_{j i}^{t+\Delta t}-\frac{\lambda_{k}}{e_{k}} T_{k i}^{t+\Delta t}=\frac{m_{c} C_{p c}}{S} T_{c i}^{t}
\end{gathered}
$$

- At the kapok wool level

$$
\begin{aligned}
& \frac{m_{k} C_{p k}}{S} \times \frac{T_{k i}^{t+\Delta t}-T_{k i}^{t}}{\Delta t}=\frac{\lambda_{k}}{e_{k}}\left(T_{c i}^{t+\Delta t}-T_{k i}^{t+\Delta t}\right)+h_{0 i n t}\left(T_{0}^{t+\Delta t}-T_{k i}^{t+\Delta t}\right) \\
& \left(\frac{m_{k} C_{p k}}{S}+\frac{\lambda_{c}}{e_{c}}+\frac{\lambda_{k}}{e_{k}}\right) T_{k i}^{t+\Delta t}-\frac{\lambda_{c}}{e_{c}} T_{c i}^{t+\Delta t}-h_{0 i n t} T_{0}^{t+\Delta t}=\frac{m_{k} C_{p k}}{S} T_{k i}^{t}
\end{aligned}
$$

- Within the pot

$$
\begin{aligned}
& \frac{m_{w} C_{w}}{S} \times \frac{T_{0}^{t+\Delta t}-T_{0}^{t}}{\Delta t} \\
& =h_{0 i n t}\left(T_{0}^{t+\Delta t}-T_{k j}^{t+\Delta t}\right)+h_{0 i n t}\left(T_{0}^{t+\Delta t}-T_{k i}^{t+\Delta t}\right)+h_{0 i n t}\left(T_{0}^{t+\Delta t}-T_{k j}^{t+\Delta t}\right) \\
& +h_{0 i n t}\left(T_{0}^{t+\Delta t}-T_{k i}^{t+\Delta t}\right)+h_{0 i n t}\left(T_{0}^{t+\Delta t}-T_{k j}^{t+\Delta t}\right) \\
& \left(\frac{m_{w} C_{w}}{S \Delta t}+\sum h_{0 i n t i j}\right) T_{0}^{t+\Delta t}-h_{0 i n t i j} T_{k i}^{t+\Delta t}-h_{0 i n t} T_{k j}^{t+\Delta t}=\frac{m_{w} C_{w}}{S \Delta t} T_{0}^{t}
\end{aligned}
$$

The algebraic Equations (14)-(23) can be written in the form of a system of equations as follows

$$
A T^{t+\Delta t}=T^{t}
$$

- Initial conditions

A $t=0, T_{0}=90^{\circ} \mathrm{C}$.

$$
T_{f}=T_{c}=T_{k}=T_{a m b}
$$

\subsection{Solving the System of Equations}

At $t_{0}+\Delta t$, we assigned an arbitrary value to the temperatures on components of the pressure cooker. The heat transfer coefficients (convective, radiative) are thus calculated. The resolution of the system of algebraic Equations (3)-(7) leads to new values of the temperature of the components of the pres- 
sure cooker which are compared with the arbitrary value. If the difference between these two temperatures is greater than the desired precision, the values of the calculated temperatures replace the arbitrary value and the procedure described below is repeated until the convergence is obtained. The convergence was obtained when the following criterion was satisfied:

$$
\frac{T^{t+\Delta t}-T^{t}}{T^{t+\Delta t}} \leq 10^{-3}
$$

\section{Results and Discussion}

\subsection{Model Validation}

Using the methodology described in Section 2.4, we obtain the numerical curve of hot water cooling under the conditions: Hot water initial temperature: $90^{\circ} \mathrm{C}$, ambient temperature: $25^{\circ} \mathrm{C}$, kapok wool density: $50 \mathrm{~kg} / \mathrm{m}^{3}$, kapok wool thickness: $15 \mathrm{~cm}$. This numerical curve is then compared to the hot water cooling curve obtained experimentally under the same conditions (Figure 4).

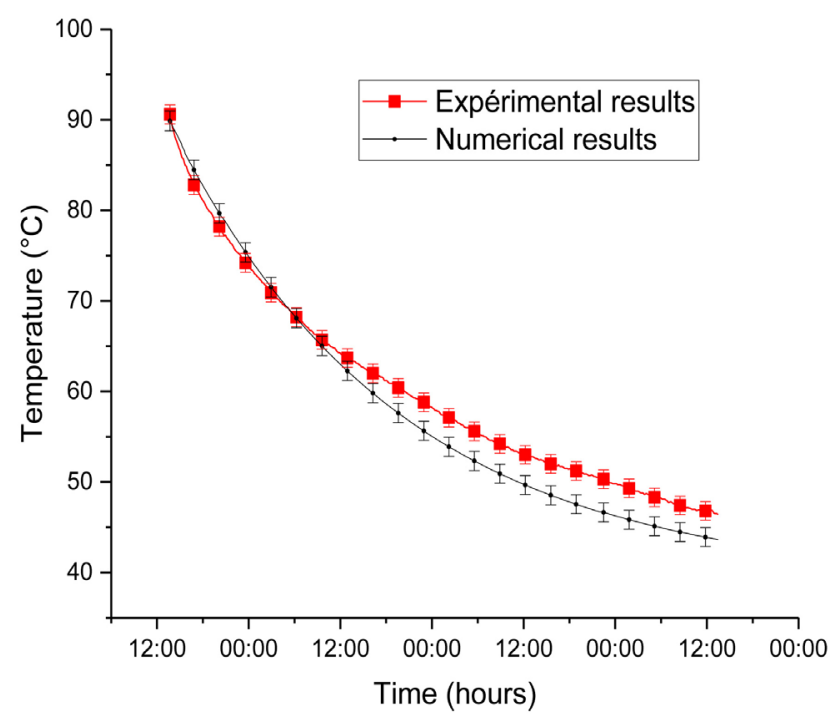

Figure 4. Model validation (hot water initial temperature: $90^{\circ} \mathrm{C}$, ambient temperature: $25^{\circ} \mathrm{C}$, kapok wool density: $50 \mathrm{~kg} / \mathrm{m}^{3}$, kapok wool thickness: $15 \mathrm{~cm}$ ).

We note a good qualitative agreement between these two results. The discrepancies do not exceed $5 \%$ and are due to the various empirical correlations used for the calculation of the heat transfer coefficients.

\subsection{Influence of Kapok Wool Thickness and Density on the Pressure Cooker Operation}

Figure 5 shows the influence of the thickness $e_{k}$ (for 1 to $20 \mathrm{~cm}$ ) of kapok wool on the cooling curve of the hot water contained in the pressure cooker. The initial temperature inside the pot is taken at $90^{\circ} \mathrm{C}$ and the outside temperature is $25^{\circ} \mathrm{C}$. 


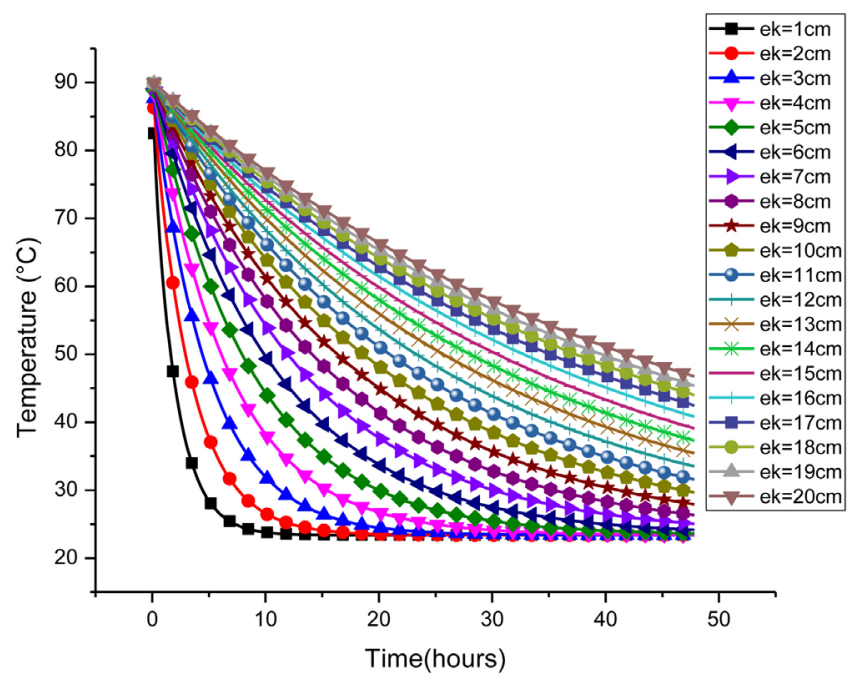

Figure 5. Influence of the thickness of the kapok wool on the cooling curve of the hot water.

We note that the temporal evolution of the water temperature decreases rapidly to tend asymptotically towards a constant value for small thicknesses of kapok wool $(1,2,3,4$ and $5 \mathrm{~cm})$. This leads to rapid cooling of hot water for low values of the thickness of the insulation. For large thicknesses of kapok wool, particularly from $15 \mathrm{~cm}$, we note that the cooling curve flows to straight lines, which indicates a low cooling of the hot water over time. This result is explained by the fact that at low thickness, the thermal resistance of the insulating material is low, which increases transfers to the outside environment.

Figure 6 shows the influence of the density (for 5 to $50 \mathrm{~kg} / \mathrm{m}^{3}$ ) of kapok wool on the cooling curve of the hot water contained in the pressure cooker. The initial temperature inside the pot is taken at $90^{\circ} \mathrm{C}$ and the outside temperature is $25^{\circ} \mathrm{C}$.

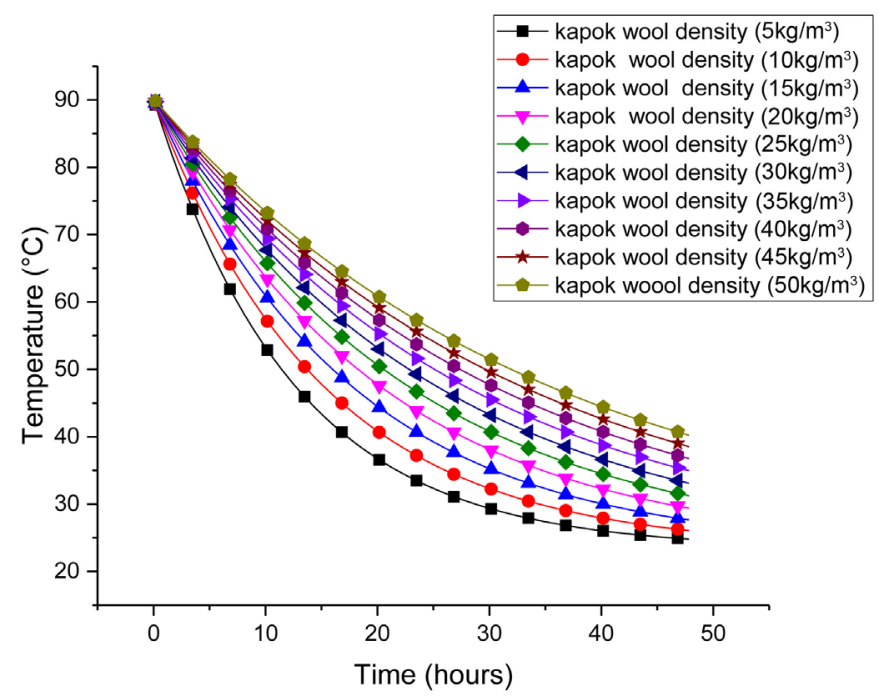

Figure 6. Influence of the density of the kapok wool on the cooling curve of the hot water. 
As in the previous case, it can be seen that the increase of the kapok wool density leads to poor cooling of the hot water over time. On the other hand, for low density value, a very rapid cooling of the hot water is observed. This result is due to the fact that at low density, the thermal diffusivity of the insulating material is high, which increases transfers to the outside environment.

\subsection{Simulation of the Pressure Cooker Operation with Meteorological Data from the City of Ouagadougou}

\subsubsection{Monthly Change in Ambient Air Temperature}

Figure 7 shows the monthly change in ambient air temperature following a seasonal cycle at Ouagadougou.

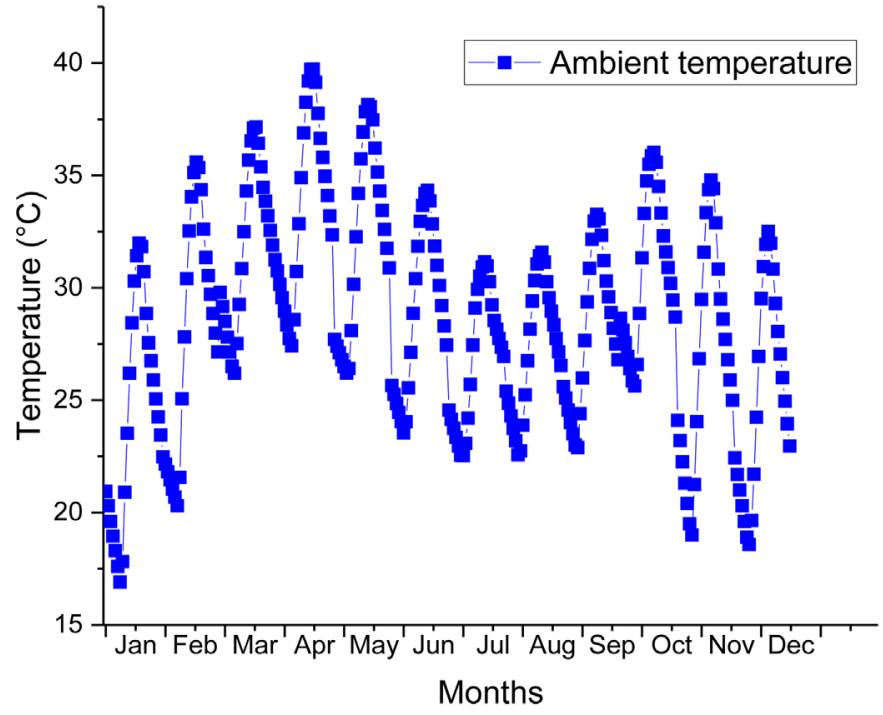

Figure 7. Ambient temperature of the typical year [19].

We note that the highest temperatures are observed in March April and May. The maximum temperature was recorded during the month of April and reached the value of $40^{\circ} \mathrm{C}$. The lowest temperatures are observed during the months of December, January and August. January is the coldest month with a maximum and minimum temperature of $32^{\circ} \mathrm{C}$ and $16^{\circ} \mathrm{C}$ respectively.

\subsubsection{Influence of the Hottest and Coldest Months on the Operation of the Pressure Cooker}

Figure 8 shows the influence of the hottest and coldest months on the operation of the pressure cooker. The initial temperature inside the pot is taken at $90^{\circ} \mathrm{C}$.

We notice that there is a similar change in the cooling curve for the two months. The difference between the two curves is more pronounced for the high times because of the temperature gradient between the two months. However, the transfers are more important for the month of January which present lower temperatures. The GAP in final temperatures between the two months is approximately $4^{\circ} \mathrm{C}$, which is relatively small compared to the initial temperature of the hot water. 


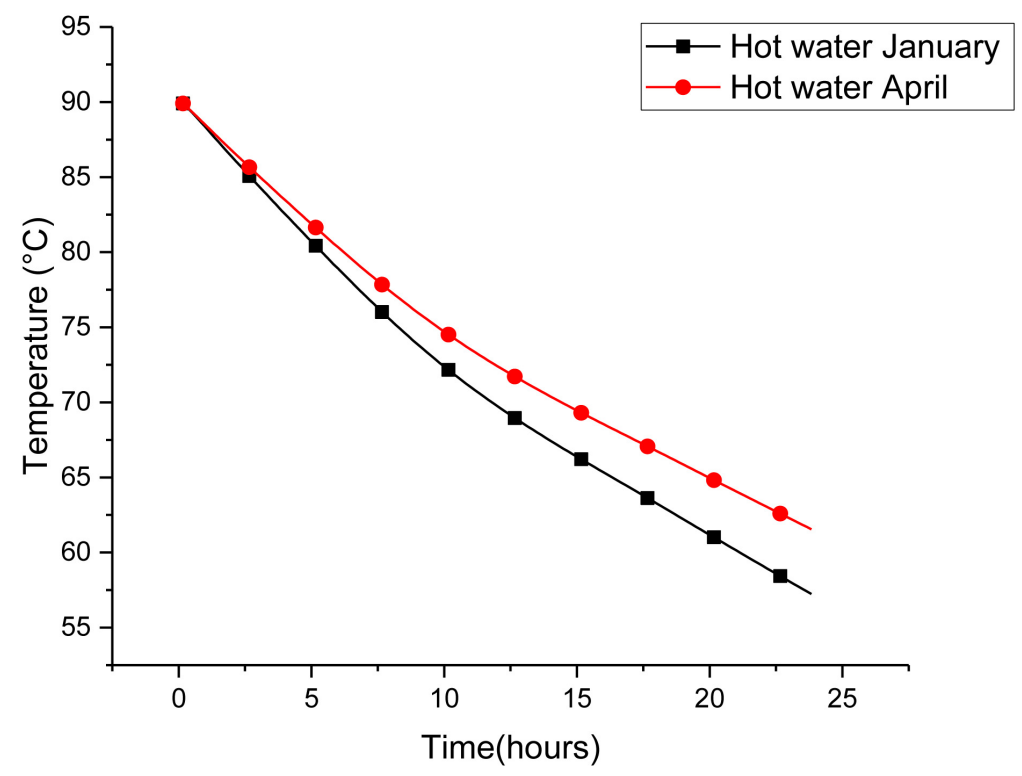

Figure 8. Influence of the hottest and coldest mounts on the cooling curve of the hot water.

\subsubsection{Influence of the Hottest Month on the Wall of the Pressure Cooker}

Figure 9 shows the influence of the hottest month on the wall of the pressure cooker. The initial temperature inside the pot is taken at $90^{\circ} \mathrm{C}$.

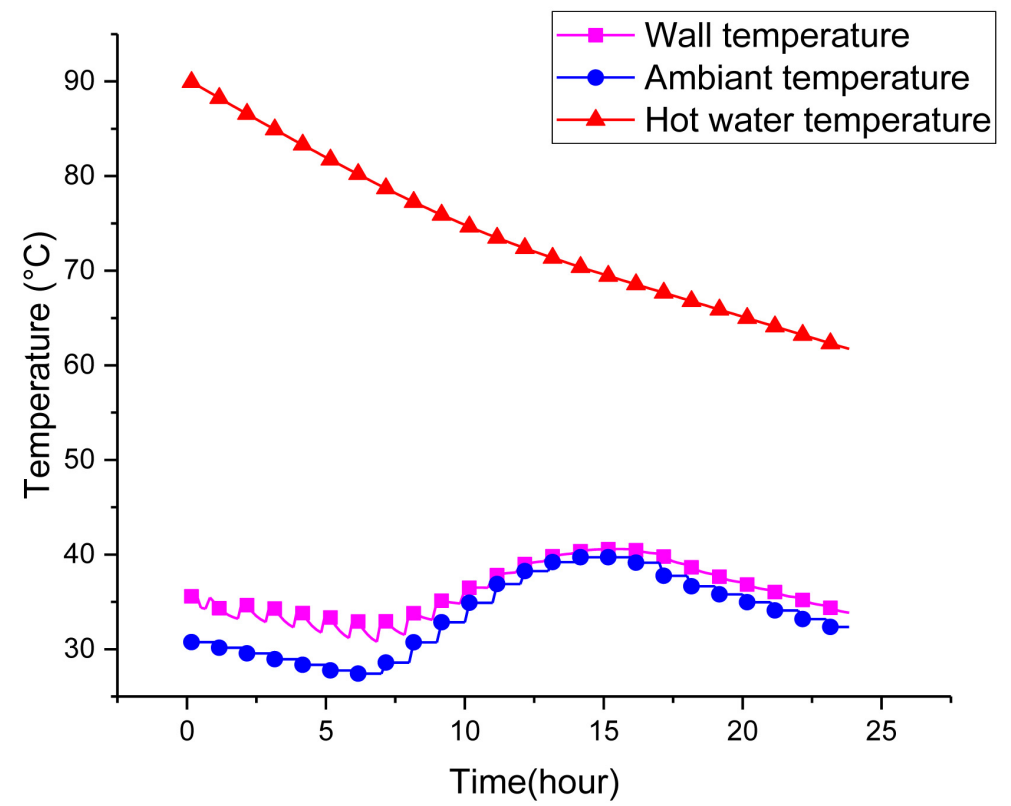

Figure 9. Influence of the hottest and coldest mounts on the cooling curve of the hot water.

We note that the temperature of the wall follows that of the ambient air which reaches a maximum between $12 \mathrm{~h}$ and $15 \mathrm{~h}$ because of the sunshine. Despite the fluctuations in the wall temperature, it can be seen that the cooling curve of the hot water is not disturbed, which shows the effectiveness of the insulation. 


\subsubsection{Influence of the 12 Typical Days of the Year on the Operation of the Pressure Cooker}

Figure 10 shows the influence of the 12 typical day of year on the operation of the pressure cooker. The initial temperature inside the pot is taken at $90^{\circ} \mathrm{C}$.

The observation in Figure 10 shows that the evolution over time of the cooling curve for the typical 12 days is similar. We also note that the temperature gradient between the different cooling curves is very low from one month to the next. These results show that the use of the pressure cooker is not conditioned by climatic by climatic variations during the year.

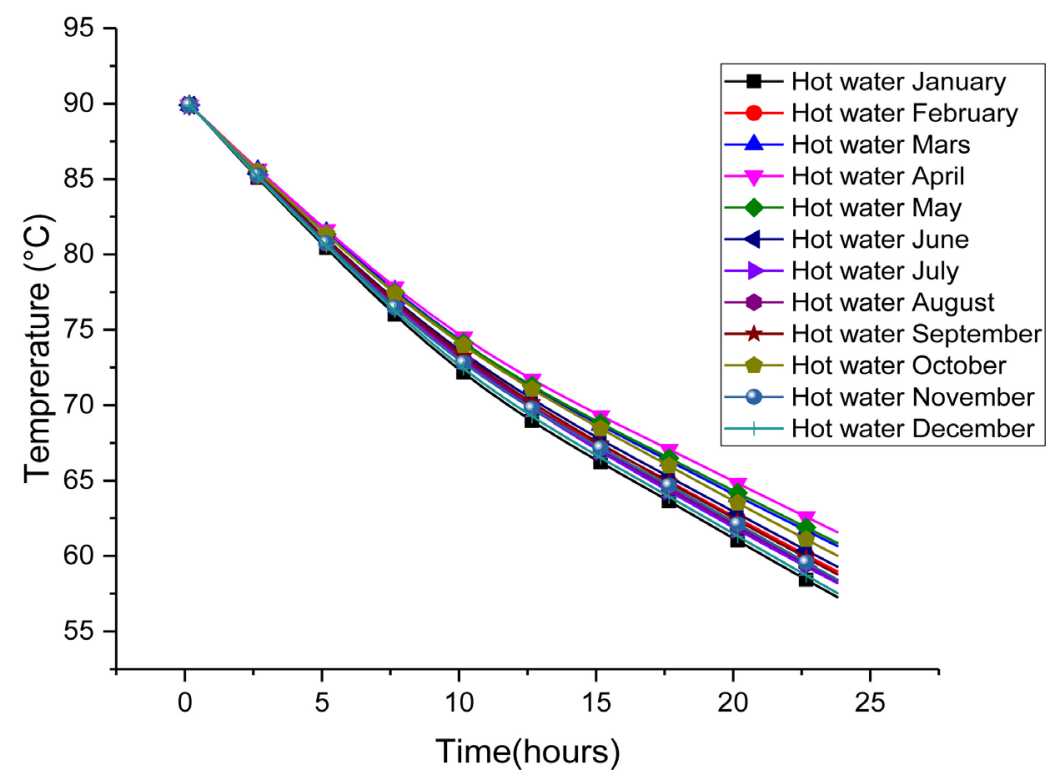

Figure 10. Influence of the 12 typical days of year on the cooling curve of the hot water.

\section{Conclusions}

A metallic pressure cooker insulated with kapok wool has been numerically investigated in the present work. The numerical methodology is based on the nodal method and the transfer equations obtained by making an energy balance on each node have been discretized using an implicit scheme with finite differences and resolved by the Gauss algorithm. The main results are summarized as follows:

- The pressure cooker performances are linked to the good thermophysical properties of kapok wool,

- The increase of the thickness and density of kapok wool leads to optimal operation of the pressure cooker,

- The pressure cooker operation is very little influenced by the climatic conditions of the city of Ouagadougou. Consequently, it can be used at any time of the year.

Its permanent use will considerably reduce energy consumption in the catering sector, as we have shown in our previous work. 


\section{Acknowledgements}

The authors express their deep gratitude to the Embassy of France in Burkina Faso, the National Research Fund for Innovation and Development (FONRID) and the International Science Program (ISP) of UPPSALA University for their financial support which allowed the realization of this work.

\section{Conflicts of Interest}

The authors declare no conflicts of interest regarding the publication of this paper.

\section{References}

[1] Voumbo, M.L., Wereme, A., Gaye, S., Adj, M. and Sissoko, G. (2008) Caractérisation des propriétés thermophysiques du kapok. Research Journal of Applied Sciences. Engineering and Technology, 8, 33-43.

[2] Damfeu, J.C., Meukama, P. and Jannotb, Y. (2016) Modelling and Measuring of the Thermal Properties of Insulating Vegetable Fibers by the Asymmetrical Hot Plate Method and the Radial Flux Method: Kapok, Coconut, Groundnut Shell Fiber and Rattan. Thermochemical Acta, 630, 64-77. https://doi.org/10.1016/j.tca.2016.02.007

[3] Wereme, A., Tamba, S., Sarr, M., Diene, A., Diagne, I., Niang, F. and Sissoko, G. (2010) Caractérisation des isolants thermiques locaux de type sciure de bois et kapok: Mesure de coefficient global d'échange thermique de la conductivité thermique. Jounal des Sciences, 10, 39-46.

[4] Wang, F. (2009) Comparisons of Thermal and Evaporative Resistances of Kapok Coats and Traditional Down Coats. Fibres \& Textiles in Eastern Europe, 18, 88-92.

[5] Nooruddin, M.F. and Puad, N.H.A. (2014) Effectiveness of Kapok Fiber (Ceiba pentandra) as Roof Insulation for Residential Buildings in Hot Climate. Australian Journal of Basic and Applied Sciences, 5, 86-91.

[6] Adulkareem, S., Ougounmodede, S., Aweda, J.O., Abdulrahim, A.T., Ajiboye, T.K., Ahmed, I.L. and Adebisi, J.A. (2016) Investigation of Thermal Insulation Properties of Biomass Composites. International Journal of Technology, 7, 989-9996. https://doi.org/10.14716/ijtech.v7i6.3317

[7] Ouedraogo, D.D., Igo, S.W., Compaore, A., Sawadogo, G.L., Zeghmati, B. and Chesneau, X. (2020) Experimental Study of a Metallic Pressure Cooker Insulated with Kapok Wool. Energy and Power Engineering, 12, 73-87. https://doi.org/10.4236/epe.2020.122006

[8] Lagonotte, E.P., Broussely, M., Bertin, Y. and Saulnier, J.-B. (2001) Improvement of Thermal Nodal Models with Negative Compensation Capacitors. European Physics Journal of Applied Sciences, 13, 177-194. https://doi.org/10.1051/epjap:2001132

[9] Boyer, H., Chabriat, J.P., Grondin-Perez, B., Grodin-Perez, C. and Tourrand, J.B. (1996) Thermal Building Simulation and Computer Generation of Nodal Models. Building and Environment, 31, 2007-2014. https://doi.org/10.1016/0360-1323(96)00001-7

[10] Nganyaa, T., Ladevie, B., Kemajou, A. and Mba, L. (2012) Elaboration of a Bioclimatic House in Humid Tropical Region: Case of the Town of Douala-Cameroon. Energy and Buildings, 54, 105-110. https://doi.org/10.1016/j.enbuild.2012.07.025

[11] Jolliet, O. (1988) Modélisation du comportment thermique d'une serre horticole: Modèle statique de seconde géneration tenant compte des apports solaires, du vent, 
des echanges radiatifs avec le ciel. Thèse de doctorat d' ingénieur Physicien EPF.

[12] Bekkouche, S.M.E.A. (2009) Modélisation du Comportement Thermique de Quelques Dispositifs Solaires. Thèse de Doctorat en Physique, Université Abou-Bakr Belkaid de Tlemcen.

[13] Chu, Churchill, S.W. and Humbert, H.S. (1975) Correlating Equations for Laminar and Turbulent Free Convection from a Vertical Plate. International Journal of Heat and Mass Transfer, 18, 323-1329. https://doi.org/10.1016/0017-9310(75)90243-4

[14] Churchill, S.W. and Usagi, R. (1972) A General Expression for the Correlation of Rates of Transfer and Other Phenomena. AlChE Journal, 18, 1121-1128. https://doi.org/10.1002/aic.690180606

[15] Incroprera and DeWitt, D. (2002) Fundamentals of Heat and Mass Transfer. 16th Edition, John Wiley \& Son, Hoboken.

[16] Ivanova, S.M. (2013) Estimation of Background Diffuse Irradiance on Orthogonal Surfaces under Partially Obstructed Anisotropic Sky Part I: Vertical Surfaces. Solar Energy, 95, 376-391. https://doi.org/10.1109/9.402235

[17] Ramírez-Faz, J., Lopez-Luque, R. and Casares, F.J. (2015) Development of Synthetic Hemispheric Projections Suitable for Assessing the Sky View Factor on Vertical Planes. Renewable Energy, 7, 279-286. https://doi.org/10.1016/j.renene.2014.08.025

[18] Oudjedi, S., Boubghal, A., Braham Chaouch, W., Chergui, T. and Belhamri, A. (2008) Etude paramétrique d'un capteur solaire plan à air destiné au séchage. (Partie: 2). Revue des Energies Renouvelables SMSTS08, Alger, 255.

[19] Compaore, A., Dianda, B., Nana, G., Bathiebo, D.J., Zeghmati, B., Chesneau, X. and Abide, S. (2018) Modeling of Heat Transfer in a Habitat Built in Local Materials in Dry Tropical Climate. Physical Science International Journal, 17, 1-11. https://doi.org/10.9734/PSIJ/2018/38931 


\section{Nomenclatures}

$A$ : Heat transfer coefficient matrix

$C_{w}$ : Mass heat capacity of water $(\mathrm{J} / \mathrm{kg} \cdot \mathrm{K})$

$C_{m}$ : Centimeter

$C_{p}$ : Specific heat of the material $(\mathrm{J} / \mathrm{kg} \cdot \mathrm{K})$

$C_{p f}$ Specific heat of sheet steel $(\mathrm{J} / \mathrm{kg} \cdot \mathrm{K})$

$C_{p c}$ Specific heat of wood sheet $(\mathrm{J} / \mathrm{kg} \cdot \mathrm{K})$

$C_{p k}$ Specific heat of kapok wool (J/kg.K)

$C_{i}$ : Specific heat $(\mathrm{J} / \mathrm{kg} \cdot \mathrm{K})$

$C_{e q}$ : Equivalent heat capacity of the pot container (liquid, solid) $(\mathrm{J} / \mathrm{kg} \cdot \mathrm{K})$

$e_{k}$ : Thickness of kapok wool (m)

$h_{0 \text { int: }}$ Overall internal exchange coefficient of the source $\left(\mathrm{W} / \mathrm{m}^{2} \cdot \mathrm{K}\right)$

$h_{i j}$. Heat transfer coefficient between media $i$ and $j$ depending on the heat transfer mode (convection, radiation) $\left(\mathrm{W} / \mathrm{m}^{2} \cdot \mathrm{K}\right)$

$h_{r-p-c i e l}$ Coefficient of heat transfer by radiation) $\left(\mathrm{W} / \mathrm{m}^{2} \cdot \mathrm{K}\right)$

$h_{c r}:$ Heat transfer coefficient by natural convection with the outside environment $\left(\mathrm{W} / \mathrm{m}^{2} \cdot \mathrm{K}\right)$

$H$ : Pressure cooker height (m)

$L$ : Pressure cooker length $(\mathrm{m})$

$m_{w}:$ Mass of water $(\mathrm{kg})$

$m_{k i}$ : Masse of kapok $(\mathrm{kg})$

$m_{f}$ : Masse of sheet steel $(\mathrm{kg})$

$m_{c}:$ Masse of wood sheet $(\mathrm{kg})$

$N_{u}$ : Nusselt number

$L$ : Pressure cooker length $(\mathrm{m})$

$Q_{i}$ : Heat source (W)

$R_{a}$ : Raleigh number

$S$ : Surface of the section considered $\left(\mathrm{m}^{2}\right)$

$T_{i}$ : Temperature at node $i(\mathrm{~K})$

$T_{j:}$ Temperature at node $j(\mathrm{~K})$

$T_{f i}$ : Temperature at the outer node of the iron sheet $(\mathrm{K})$

$T_{f}$ : Temperature at the internal node of the iron sheet $(\mathrm{K})$

$T_{c i}$ : Temperature at the internal node at the plywood $(\mathrm{K})$

$T_{k i}$ Temperature at the internal node at the kapok level (K)

$T_{0}$ : Internal pressure cooker temperature $(\mathrm{K})$

$T_{\text {sky: }}$ Sky temperature (K)

$T_{a m b}$ : Ambient temperature (K)

$T_{f 1}$ : Temperature of the outer left side of the pressure cooker at the level of the steel sheet

$T_{\mathrm{f} 2}$ : Temperature of the inner left side of the pressure cooker at the level of the steel sheet

$T_{B}$ : Temperature of the external front face of the pressure cooker at the level of the steel sheet 
$T_{A}$ : Temperature of the inner front face of the pressure cooker at the level of the steel sheet

$T_{55}$ : Temperature of the outside right side of the pressure cooker at the level of the steel sheet

$T_{16}$ : Temperature of the inner right side of the pressure cooker at the level of the steel sheet

$T_{f}$ : Temperature of the outer rear face of the pressure cooker at the level of the steel sheet

$T_{B}$ : Temperature of the inner rear side of the pressure cooker at the level of the steel sheet

$T_{c 1}$ : Temperature of the left side of the pressure cooker at the level of the plywood

$T_{\mathrm{c} 2}$ : Temperature of the front of the pressure cooker at the level of the plywood

$T_{c 3}$ : Temperature of the right side of the pressure cooker at the level of the plywood

$T_{c 4}:$ Temperature of the back of the pressure cooker at the level of the plywood

$T_{k 1}$ : Temperature of the left side of the pressure cooker at the level of the kapok wool

$T_{k 2}$ : Temperature of the front of the pressure cooker at the level of the kapok wool

$T_{k 3}$ : Temperature of the right side of the pressure cooker at the level of the kapok wool

$T_{k 5}$ : Temperature of the back of the pressure cooker at the level of the kapok wool

$\Delta t$. Time step (s)

$T^{t+\Delta t}$ : Temperature vector at time $t+\Delta t$

$T^{t}$ : Temperature vector at time $t$

$\rho_{i}$ : Specific mass heat $\left(\mathrm{kg} / \mathrm{m}^{3}\right)$

$\lambda_{i}$ : Conductivity of sheet steel $(\mathrm{W} / \mathrm{m} \cdot \mathrm{K})$

$\lambda_{c}$ : Conductivity of wood sheet $(\mathrm{W} / \mathrm{m} \cdot \mathrm{K})$

$\lambda_{k}$ : Conductivity of kapok wool $(\mathrm{W} / \mathrm{m} \cdot \mathrm{K})$

$V_{i:}$ volume of the liquid in the pot $\left(\mathrm{m}^{3}\right)$

$V$ : Wind speed $(\mathrm{m} / \mathrm{s})$

$W$ : Pressure cooker width (m) 